\title{
The Creation Characteristics Analysis of China's Folk Opera
}

\author{
Jian Luo \\ Neijiang Normal University, Neijiang, Sichuan Province, China
}

Keywords: China's folk opera, folk opera, folk opera creation, characteristics

\begin{abstract}
Chinese folk music has a rich content and precious artistic value, is can't be matched by any country music, is the people in the long-term productive labor and social practice activities and collective creation. Chinese folk music after thousands of years of development, the accumulation of all folkities in the art of wisdom and creation ability, has distinct folk character. So should fully explore our music cultural heritage, enriching the content of folk music art, more important is to develop folk music listeners, popularize the folk music culture, and create a good environment for the folk music.
\end{abstract}

\section{Introduction}

Chinese folk music is a very unique form of art in the world. The Chinese nation for thousands of years of civilization, created a lot of good folk music culture, formed a profound meaning and content of rich folk music system. So we have to know Chinese music, not just sing some Chinese song, listen to traditional music passages, also must from the nation, history, geography Angle to study the Chinese music, to understand the characteristics of Chinese music, to understand the real meaning of the Chinese music [1]. Chinese folk music has a long history, is an important part of Chinese traditional music culture, embody the emotion, strength, will, and the pursuit of the Chinese nation.

In the development of Chinese film music on the road, as the important elements in the film music use of folk music in the film music is in constant dig deep and strengthen utilization. The folk instrumental music is music for movies with the best fertilizer, at the same time the effect that makes the finishing point. Each ethnic Musical Instruments have their own rich forms, and our folk musical instrument plays, mainly divides into four categories as wind, blow, pull string [1]. These are distinctive ethnic Musical Instruments and the style of different type of instrumental music. And Chinese contemporary popular music and folk music has great changes have taken place, pop music learning from various aspects, imitate, draw lessons from the certain factors to gain development of folk music, and has become an unstoppable trend. While folk music with era pace, to survive in innovation. "Folk music popular" is a remarkable pattern.

\section{The formation of opera music}

Chinese folk music is in the Yellow River basin as the center of the central plains music and four fields of music and foreign music interact. This we can induce four domain music, central plains music, foreign music are three major factors of Chinese folk music form.

\subsection{Four domain music.}

Refers to creation by the Huaxia Clan as the main music culture in the Yellow River outside of music cultures are all ethnic groups of the earth. And the birthplace of Chinese music culture has three big, namely, the Yellow River, the Yangtze River, Pearl River basin. In this paper mentioned before, the Yellow River basin is given priority to with the Han folkity music culture music culture [2]. And the Yangtze River basin of music culture is given priority to with Chu music culture. 


\subsection{The central plains music.}

Refers to the Yellow River basin as the center of music, it is mostly Han Chinese people living in the Yellow River basin, they are in the course of a long, through their own creation, modification, and inheritance way we have created a unique ethnic Han Chinese music culture.

\subsection{Communicate with foreign music.}

Chinese music and foreign music communication also has a long history. Since the western Zhou dynasty, has began to frequent interfold exchanges. According to the load, king mu has brought huge band trip to the west, visible, a reference to modern words to sum up the situation, can use the word "fashion". And at the time of the Han dynasty Buddhism has been introduced into the central plains, and gradually become the mainstream of Chinese religion. At the same time, the Indian music and Tianzhu has been introduced to China, and accommodation with local music, become another new music materials [2]. Messengers will be introduced from the foreign music at the same time, also brought country music to their country, and the word "match well of Chinese and western" is more a kind of explanation.

\section{The characteristics of the opera music}

Chinese folk music is mainly linear way of thinking; Column in a channel mode for the backbone voice. Due to the folk music in among the people for a long time, so has been refined over the inevitable is the most thoughtful and artistic, and content is the sincere language of the people's thoughts and feelings more, is the vivid reflection of people's life [2]. The most widely circulated mostly is a distinct, vivid image, artistic conception catchy tune. In addition, I personally think, Chinese folk music but also has the following characteristics.

\subsection{Variability.}

Since the living environment of the ethnic, cultural customs, traits of character, etc, so the same song of understanding and comprehension ability is also different. To the "embroider pouch" as an example, this piece in Shanxi Province in central and northern Shaanxi presents two different style, the former beautiful, handsome, out of the joy; The simple, depression, reveals the desolate feeling.

\subsection{Impromptu characteristics.}

Everyone with a tune of understanding and interpretation is different, therefore in the process of inheritance, joined the personal style and improvisation, which is driving force for the development of the folk music in new place. So, the impromptu sex is also a significant characteristics of folk music.

\subsection{Local characteristics.}

China's land area is broad, complex terrain, diverse climate, so music of all ethnic groups of local first performance on the dialect. China's 55 ethnic minorities, besides Chinese, other folkities are belong to their native language, songs of all folkities is fundamental key with dialects in the first place. Secondly also shows on the personality traits of people of all ethnic groups. As a northerner is frank, straightforward, so its music style is also more generous, wide.

\section{The factors influencing folk opera creation}

Folk opera as a bunch of flowers of charm of art gardens in our country have been thriving boom, but with the rapid development of social trends, but appeared restricting the disharmonic factors affecting the development of folk opera, the main Characteristics of the folk opera are:

\subsection{Economic factors.}

"Economic base determines the superstructure, is adapt to the need of the economic foundation and superstructure, what is the economic base, there will be what kind of superstructure.”Marxist 
political economics tells us that all development is inseparable from the economic support [3]. As a cultural ideological superstructure opera, is based on certain economic base, is restricted by economic factors. An opera from creation to rehearsal, need a certain amount of money.

\subsection{Multicultural factors.}

Since China's reform and opening up, rapid development Xinchuan media such as television, movies, Hong Kong and Taiwan pop music with its pure and fresh and natural style impact and influence the mainland, with the advent of this multicultural phenomenon, make people's spiritual and cultural enjoyment from single to multiple, become the objective factors which restrict the development of the folk opera [3].

\subsection{The audience's aesthetic psychology and appreciation habit.}

Due to historical reasons, the Chinese people has formed a kind of special folk psychology: on the one hand, accustomed to the outside world to return to the heart of misery Epiphany resolved, on the other hand, a strong desires in the loss of the material world to meet the spiritual world [3]. Special folk mentality has created a special folk opera art, and drama art guide and create the folk aesthetic taste and appreciation habits. "

\subsection{Literary theory factors.}

China's folk opera from formation to now, the opera theory construction seriously enough, Chinese opera history books yet, the creation of the folk opera theory also less; the so-called literary criticisms, to report good news not suffer, and much is echoing and flattering. Folk opera couldn't keep up with the theory of construction, development of literary criticism is not sound, to some extent, restricted the development of the folk opera.

\subsection{The talent factor.}

Cultivate a good opera talents, need to take at least ten years, due to certain factors, folk opera hard to cultivate many talented, signed at theaters abroad rather than stay at home more stage, it to a certain extent influence the development of the folk opera.

\section{The creation of the folk opera}

Chinese folk music is the people in the long-term production and social practice of collective creation, it reflects the bottom, the most ordinary people's life. China is a multi-ethnic country, folk music has a long history, and the Chinese people since ancient times has a habit of communication fusion, open-minded and achieve mastery through a comprehensive study of the spirit of all rivers run into sea. Chinese traditional music through thousands of years of development, the accumulation of various folkities art wisdom and creativity ability, has the distinctive folk character, they mutually in the continuous communication and integration, mutual competition and development [4]. With a variety of other art the same, ethnic music also has experienced a long developing process, gradually merged the essence of the surrounding folk music and evolved the unique folk music art and music tradition, such as southern folk songs, northeast Errenzhuan, etc. Of all ethnic groups of art in the history of the evolution of the doomed to absorb other ethnic characteristics, complement each other, common development, so that every folk art forever, as long as is a good part of our folk music, it will be accepted by other nation, and even, so the folk music is a natural, continuous development. Some people have already by the history of the long slowly fuzzy, but the legacy of their artistic wealth but have not be eliminated, the presence of these ethnic groups have the significance, the existence of folk music and art also has a great value.

Era in the development, in advance, the idea of people changes in thinking and life rhythm, people pursuit of music appreciation and habits are also to the folk music put forward new requirements, because the world of art is that coincide with The Times, to fully tap the Chinese music and cultural heritage, enriching the content of folk music art, and reform of ethnic Musical Instruments, based on folk instrumental music, adhere to the correct development direction, to ensure its healthy 
development. To the development of folk music, only with a high level of performance is not enough, more important is to create closer to people's folk songs of life [4]. Make people feel the rich connotation of Chinese traditional culture, to promote the urban cultural taste of people, eventually make widely around the folk music culture in the promotion and spread. Only in this way can the traditional folk music culture to survive, continue, innovation and development, will be more artistic vitality. In general, folk song creation has the following several characteristics:

\subsection{Absorbing drama essence.}

To create a popular folk opera with Chinese characteristics, the audience, actively absorb the essence of Chinese opera culture. In the historical development of Chinese opera, and experienced a drama of song and Yuan dynasties, the Yuan dynasty period, middle period of Ming dynasty, Qing dynasty legend middle of local opera so few boom, guide and create the folk aesthetic taste and appreciation habits, the Chinese opera music into opera, are very popular with Chinese audiences [5]. In the $1990 \mathrm{~s}$ on the folk opera of "the party's daughter," like a cuckoo in the winter, brought new vigor to the downturn in recent years, the opera stage, make people see the folk opera of new hope. It boldly absorb the traditional opera and folk music, choose plate cavity and songs with the combination of music forms, will be beautiful lyric, euphemism is exquisite tones of Jiangxi folk songs and grand, powerful stiffness of Shanxi Puzhou opera of Shanxi Province, the combination of created there are both folk verve, and personality characteristics of music style, is refreshing.

\subsection{In accordance with the average Chinese audience aesthetic view.}

Life is the source of music creation, the people is the carrier of life, they have sprung up around countless exciting characters and stories, they reflect the real life, meet the demand of aesthetic culture [5]. Opera "white-haired girl", "Hei" successes, lies in its subject, fully using the real life happened beside of ordinary people, certain things in certain circumstances as material, the feeling and experience their bitterness and sufferings, create accord with the aesthetic psychology and appreciation habit of opera works. Folk opera to survival and development, therefore, must let the common people to accept, love, love. As dramatist even said: "in order to promote the development of new opera, opera, we should to a contest to see who the things more crowd favorite, who spend money economy (something creative or complete), of course, the result of this competition, I'm sure the new opera will be more prosperity, and greater achievements. "

\subsection{The government support and media participation.}

In today's money, cultural consumption is an era of entertainment, opera art lost market, to cultivating and developing as a high art form of opera, the government must increase the intensity of support, to engage in opera troupes provide certain financial support, to establish funds safeguard mechanism, work out their worries [6]. On public opinion direction, urged guidance, increase publicity, call and opera also like "Peking Opera into classroom", into the primary and secondary school music class. The government use of modern media, popularize knowledge of opera, from central to local TV stations are required to offer opera channel; Demand in the Chinese music "young singer competition" top contest, the contestants have to sing a song of China folk opera excerpts.

\subsection{The style characteristics.}

Folk opera is based on the folk philosophy and traditional culture of the Chinese nation, on the basis of will and opera, ethnology, history, literature, linguistics, literary disciplines such as many kinds of people from each other, complement each other, using the people familiar with the form of drama performances, music, language, etc. , to create Chinese opera structure as the matrix, the folk music as material composition, style formed on the characteristic, singing, dancing, reading, do pay equal attention to, and deeply opera are very popular among the people of the nation. "The white-haired girl", "Hei marriage" is a good example of this is because they have strong folk style, laid the foundation for the development of Chinese folk opera, affected the generation after generation, become "evergreen" in the folk opera [6]. If derivative, don't study this folk philosophy and cultural tradition, can't form their own style characteristic. 


\subsection{The art system.}

The development of China's folk opera, although the past hundred years, but didn't like opera in the world culture to form unique system, therefore, in the development of its rich, more should learn opera music, drama comprehensive performing arts, performing arts, drama, etc. , gradually establish a theory, creation and performance of Chinese folk opera system, lay the foundation for the development of folk opera to a higher level.

\subsection{Based on the nation to the world.}

To move towards the world, China's folk opera must have their own folk style and characteristics, cannot think that opera is western art, should be to the all-round, the more "foreign" can integrate with the world. It is only in own unique artistic charm, can add luster on the world stage. Such as Mei Lanfang led China Beijing Opera troupe to perform in his early years, everywhere is in a unique folk style and beating performance impressed the audience, to western eyes, amazing [7]. After the reform and opening up, Henan opera has been innovating place such as drama to the world stage, with its strong local opera features was warmly welcomed. Therefore, as a measure of a country and a nation symbol of opera art level, more should take its own unique folk style characteristic, complete system of art, a positive attitude towards the world, to become the world's opera art flower in blossom unique charm of art.

\subsection{The integration of different music.}

No matter for more than one hundred years, musical bumpy journey, it is how the glory and pride; Regardless of musical theory construction of books, musical masters of stars, but the musical development up to now, it is still the mainstream of the "realism aesthetics" and forms of expression of "experience aesthetics", is still not beyond the original Shakespeare, Moliere, Ibsen drama for the mainstream ideas and aesthetic pursuit [7]. Because their art, nature and aesthetic appeal is consistent, their spirit is consistent with the inherent law and perform, their humanity care and compassion is consistent with the world, although they are on the forms and expounds concept have a variety of different or even worlds apart.

\section{Conclusion}

Chinese folk music is an important part of Chinese traditional music culture. Therefore, no matter in the genre of music and form, on the tone and style of the music, presents colorful appearance. Music creation, theories, the above, as well as the art of creation and performance experience, also has a profound accumulation. Study the characteristic of folk music, folk music special regularity, to create new socialist folk music has the vital significance. Extensive and profound Chinese music culture and folk music is its core part, study ethnic music and understand music, to inherit and carry forward the folk music, make our folk music culture more light is the mission of contemporary youth do not slack off.

\section{References}

[1] G.H. Deng, The development of Chinese national folk music, Beijing: higher education press, 2008, vol. 3, pp. 12-14.

[2] Y.W. Cao, Ethnic style of folk music, Film \& literature, 2010, vol. 1, pp. 101-105.

[3] X.Y. Li, Popular music of ethnic music, Music research, 2009, vol. 6, pp. 82-84.

[4] Y.F. Lu, National folk music research, Shanghai: Culture and art publishing house, 2011, vol. 5, pp. 33-37.

[5] X.W. Xiong, Ethnic music for the reference of popular music, Jiangsu: Yangtze normal university music institute, 2003, vol. 5, pp. 63-66.

[6] S.H. Xu and Ch.Y. Liu, The national elements of popular music, Music research, 2008, vol. 7, pp. 175-177.

[7] Ch. L. Ming, Chinese national music appreciation, Beijing: higher education press, 2005, vol.8, pp. 50-53. 